\title{
ANALISIS VEGETASI DI TAMAN NASIONAL GUNUNG MERAPI
}

\author{
Vegetation Analysis In Taman Nasional Gunung Merapi
}

\author{
Oleh: \\ Anggiyani Fabilah Parwati ${ }^{1}$, Zahra Aptari ${ }^{1}$, Rohmi Dwi Saputri ${ }^{1}$, Ahmad Malik Akbarudin ${ }^{1}$, \\ Arsy Gita Kirana ${ }^{1}$, Seftiana Tri Wahyuni ${ }^{1}$ \\ ${ }^{1}$ Jurusan Pendidikan Biologi, Fakultas Matematika dan Ilmu Pengetahuan Alam, \\ Universitas Negeri Yogyakarta \\ anggiyani17@gmail.com; aptari19@gmail.com; dwinana26@gmail.com; \\ ahmadmalikakbarudin@gmail.com; arsy.g.kirana@gmail.com; seftianatriw013@gmail.com
}

Diterima 19-12-2019, direvisi 31-01-2020, disetujui 01-02-2020

\begin{abstract}
ABSTRAK
Keanekaragaman merupakan kumpulan seluruh penghuni biosfer yang berhubungan antara satu dengan yang lainnya dan saling mempengaruhi. Keanekaragaman jenis tumbuhan sebagian besar terdapat di hutan tropis khususnya pegunungan. Struktur hutan tropis dapat menciptakan keanekaragaman jenis yang tumbuh didalamnya. Analisis vegetasi tumbuhan di Taman Nasional Gunung Merapi ini bertujuan untuk mengetahui keanekaragaman hayati dan mengetahui struktur dan komposisi vegetasi hutan tersebut. Analisi Vegetasi ini mendapatkan hasil yaitu ada 4 habitus yang ada, yaitu lumut-lichen, semak, herba, dan Pohon. Indeks Nilai Penting berfungsi sebagai indikator seberapa penting tumbuhan itu ada di sana. Tumbuhan yang memiliki INP paling tinggi pada habitus masing-masing yaitu Pogonatum sp dengan INP sebesar 203,314\% pada habitus Lumut-Lichen. Ageratina repair dengan INP 124,761\%. pada habitus Herba , Brachiria mutica dengan INP 141,488\% pada habitus Semak dan Syzygium oleina dengan INP 111,333\% pada habitus pohon. Tingginya INP menunjukan bahwa spesies tersebut dapat menyesuaikan diri terhadap lingkungan sekitar dibandingkan dengan spesies lainnya.
\end{abstract}

Kata Kunci: Analisi vegetasi, Gunung Merapi, keankaragaman.

\section{ABSTRACT}

Diversity is a collection of all biosphere inhabitants that are related to one another and influence each other. Plants diversity is mostly found in tropical forests, especially mountains. The structure of tropical forests can create a diversity of species that grow in this area. Analysis of plant vegetation in Mount Merapi National Park aims to determine biodiversity and determine the structure and composition of the forest vegetation. Vegetation analysis obtained results, there were 4 habitus, namely moss-lichen, bush, herb, and stand. The Importance Value Index serves as an indicator of how important the plant is there. The plants that have the highest INP in each habitus are Pogonatum sp with an INP of $203.314 \%$ in Lumut-Lichen habitus. Ageratina repair with 124,761\% INP. in Herbaceous habitus, Brachiria mutica with INP 141,488\% in Bush habitus and Syzygium oleina with INP 111,333\% in tree habitus. The high INP shows that the species can adapt to the surrounding environment compared to other species.

Keywords: Vegetation analysis, Mount Merapi, diversity

\section{PENDAHULUAN}

Pada saat ini dengan berbagai kepentingan, ekologi berkembang sebagai ilmu yang tidak hanya mempelajari apa yang ada dan apa yang terjadi di alam. Ekologi berkembang menjadi ilmu yang mempelajari struktur dan fungsi ekosistem, sehingga dapat menganalisis dan memberi jawaban atas kejadian-kejadian yang ada di alam.

http://doi.org/10.20886/jped.2019.5.2.107-112
Indonesia dikenal dengan mega biodiversitas yang sangat tinggi (Maharadatunkamsi, Prakara dan Kurnianingsih, 2015). Keanekaragaman hayati adalah istilah yang digunakan sebagai derajat keanekaragaman sumber daya alam hayati, yaitu jumlah dan frekuensi dari ekosistem, spesies, serta gen di suatu daerah. Keanekaragaman hayati adalah keberagaman berbagai jenis sumber daya alam hayati, baik 
tumbuhan maupun hewan yang ada di muka bumi (Mardiastuti, 1999).

Taman Nasional Gunung Merapi (TNGM) adalah kawasan pelestarian alam karena memiliki ekosistem asli. Kawasan tersebut merupakan perpaduan ekosistem gunung berapi dengan hutan dataran tinggi, serta pegunungan. Kawasan ini dikelola dengan sistem zonasi. Hal ini dapat dimanfaatkan untuk tujuan penelitian, ilmu pengetahuan, pendidikan, budidaya, pariwisata dan rekreasi. Penetapan Kawasan tersebut sebagai Taman Nasional Gunung Merapi berkaitan dengan Surat Keputusan Menteri Kehutanan No. 134/ Menhut-II/2004 pada tanggal 4 Mei 2004 yang berisi tentang perubahan Fungsi Kawasan Hutan Lindung, Cagar Alam dan Taman Wisata Alam. Hutan Gunung Merapi memiliki luas sebesar \pm 6.410 ha. Kawasan ini terletak di Kabupaten Magelang, Boyolali, Klaten Provinsi Jawa Tengah serta Kabupaten Sleman, Provinsi Daerah Istimewa Yogyakarta (Susantyo, 2011).

Menurut (Lakitan,2002) klasifikasi iklim menurut Schmidt-Ferguson Tipe Hutan di Gunung Merapi adalah tipe hutan rimba karena memiliki iklim yang agak basah. Hutan Merapi adalah salah satu hutan Konservasi, hutan konservasi adalah hutan yang memiliki ciri khas tertentu dan mempunyai fungsi pokok yaitu sebagai pengawetan keanekaragaman tumbuhan dan satwa serta ekosistemnya (Solfiyeni, Chairul, dan Masdalena Marpaung. 2016)

Tujuan dilakukannya penelitian ini adalah untuk menganalisis vegetasi dengan mengetahui Indeks Nilai Penting, Nilai Kerapatan jenis, dan Indeks Keanekaragaman Shanonn-Weinner yang perhitungannya dilakukan dengan mengidentifikasi dan mendata tumbuhan di Stasiun Penelitian Taman Nasional Gunung Merapi dengan mengelompokkan spesies-spesies tersebut ke dalam kelompok empat habitus yaitu
Lumut,/Lichenes, Paku/Herba, Semak/Perdu, dan Pohon/Pohon.

Dengan mengetahui Nilai Kerapatan jenis, Indeks Nilai Penting, dan Indeks Keanekaragaman dapat diketahui persebaran jenis habitus yang dominan di wilayah Stasiun Penelitian Taman Nasional Gunung Merapi.

\section{METODOLOGI PENELITIAN}

\section{A. Waktu dan Tempat Penelitian}

Pengambilan data ini dilakukan pada tanggal 11 Oktober 2019. Lokasi pengambilan data dilakukan di kawasan Taman Nasional Gunung Merapi. Identifikasi dilakukan di Stasiun 6 kawasan Taman Nasional Gunung Merapi. Titik koordinat lokasi stasiun 6, plot 1 (S07³4'43.5" E110²6'34.9"), plot 2 (S07³4'44.1" E110²6.35'.1").

\section{B. Alat}

Alat yang digunakan dalam pengambilan data adalah Global Positioning System (GPS) sebagai sistem navigasi yang dapat menyediakan posisi secara instan, kecepatan dan informasi waktu, lux meter untuk mengukur besarnya intensitas cahaya, thermometer untuk mengukur suhu, kamera digital untuk mendokumentasikan kegiatan, meteran untuk mengukur dalam skala meter, kompas sebagai penunjuk arah, buku panduan sebagai pedoman dalam pelaksanaan penelitian, patok kayu untuk membuat batas, dan alat tulis untuk menulis hasil penelitian.

\section{Metode}

Metode Dalam penelitian ini mengikuti (Fachrul, 2008), analisis vegetasi dilakukan dengan menggunakan metode Quadrat sampling. Quadrat sampling merupakan serangkaian kuadrat dari ukuran yang ditetapkan di habitat kemudian diidentifikasi dan dicatat, pembuatan petak kudrat (quadrat sampling) ukuran $16 \mathrm{~m} \times 16 \mathrm{~m}$ untuk jenis tumbuhan, sebanyak 2 plot yang diletakkan 
Analisis Vegetasi Di Taman Nasional Gunung Merapi A.F.Parwati, Z.Aptari, R.D. Saputri, A.M.Akbarudin, A.G.Kirana, S.T.Wahyuni

secara purposive sampling (lokasi yang menjadi pertimbangan tertentu).

Data yang telah didapatkan selanjutnya di analisis untuk mendapatkan nilai Kerapatan jenis, Kerapatan Relatif, Frekuensi, Frekuensi Relatif, Dominasi, Dominasi Relatif, Indeks Nilai Penting,dan Indeks Keanekaragaman dari tiap-tiap jenis vegetasi tumbuhan dengan menggunakan rumus :

$\operatorname{Kerapatan}(\mathrm{K})=$

Jumlah Individu Suatu Spesies Luas Seluruh Petak

Kerapatan Relatif $(\mathrm{KR})=$

$\frac{\text { Kerapatan setiap spesies }}{\text { jumlah kerapatan semua spesies }} \times 100 \%$

Dominansi Relatif $=$

$\frac{\text { Dominansi setiap spesies }}{\text { jumlah dominansi seluruh spesies }} \times 100 \%$

Frekuensi $(\mathrm{F})=$

Jumlah Petak dijumpai suatu spesies jumlah seluruh petak

Frekuensi Relatif $(\mathrm{FR})=$

$\frac{\text { Frekuensi setiap spesies }}{\text { Jumlah Frekuensi seluruh Spesies }} \times 100 \%$

Indeks Nilai Penting $($ INP $)=$

Kerapatan Relatif + Dominansi Relatif + Frekuensi Relatif

Data jumlah individu dan famili yang diperoleh kemudian di analisis menggunakan indeks Keanekaragaman Shannon-Wiener. Analisis indeks Keanekaaragaman ShannonWiener dilakukan menggunakan rumus sebagai berikut (Hill, dkk., 2005):

$$
H^{\prime}=\sum_{i=1}^{n}\left(\frac{n i}{N} \ln \frac{n i}{N}\right)
$$

Keterangan:
H' = Indeks Keanekaragaman Shannon-Wiener

$\mathrm{ni}=$ Jumlah Individu (n)

$\mathrm{N}=$ Jumlah Keseluruhan Individu

Indeks Shanon-Wiener memiliki indikator sebagai berikut :

\begin{tabular}{l|l}
\hline \multicolumn{1}{l}{ Indeks Shanon-Wiener } & \multicolumn{1}{l}{ Tingkat Keanekaragaman } \\
\hline$H^{\prime}<1,5$ & Rendah \\
$1,5 \leq H^{\prime} \geq 3,5$ & Sedang \\
$H^{\prime}>3,5$ & Tinggi. \\
\hline
\end{tabular}

\section{HASIL DAN PEMBAHASAN}

Lokasi stasiun 6 berada di daerah yang merupakan daerah lereng pegunungan yang terjadi suksesi secara sekunder secara geografis terletak di sekitar koordinat Titik koordinat lokasi stasiun 6, plot 1 (S07 $34^{\circ} 43.5^{\prime \prime}$ E110²6'34.9"), plot 2 (S07³4'44.1" E110²6.35'.1").

Dari hasil analisis vegetasi pada Stasiun Penelitian, vegetasi yang terdapat di daerah sekitar gunung merapi ada 31 jenis, dengan 3 jenis Lumut, 13 jenis Herba, 9 jenis Semak dan 6 jenis Pohon. Jenis tumbuhan yang mendominasi pada Habitus Lumut adalah Pogonatum sp. dengan INP 203,314\% dengan INP tersebut Pogonatum sp. menjadi INP tertinggi habitus Lumut di area tersebut. Habitus Herba didominasi Ageratina reparia dengan INP 124,761\% menjadi INP tertinggi habitus Herba di area tersebut, Habitus Semak yang mendominasi Brachiria mutica dengan INP 141,488\% menjadi INP tertinggi habitus Semak di area tersebut, habitus pohon didominasi Syzygium oleina dengan INP $111,333 \%$ menjadi INP tertinggi habitus Pohon di area tersebut hasil analisis vegetasi disajikan pada Tabel 1.

\section{Pogonatum sp.}

Pogonatum sp. (INP 203,314\%) mampu hidup di tempat yang gundul di atas cadas, hingga ada yang melekat di atas 
pepohonan. Pogonatum sp. dapat menjaga kelembaban udara, menjaga porositas tanah, serta pengikat air. Lumut ini di jumpai di stasiun 6 menempel di pohon maupun yang berada pada batuan cadas. Pogonatum sp. umumnya ditemukan di daerah hutan dataran rendah, hutan pegunungan dan dapat tumbuh di daerah terbuka dengan substrat tanah dan bebatuan (Windadri, 2009).

\section{Ageratina reparia}

Ageratina reparia (INP 124.761\%) banyak terdapat di stasiun 6 karena dipengaruhi oleh beberapa faktor; antara lain memiliki kemampuan reproduksi, adaptasi yang tinggi terhadap lingkungannya, keadaan tempat tumbuhnya sedikit ternaungi, akar menyebar sehingga dapat menyerap lebih banyak unsur hara. Menurut Ewusie (1990), vegetasi lantai akan lebih subur di tempat hutan terbuka atau di tempat lain yang tanahnya lebih banyak mendapat cahaya. Faktor-faktor inilah yang mengakibatkan tumbuhan Ageratina riparia memiliki jumlah yang banyak dan penyebaran yang luas.

\section{Brachiria mutica}

Brachiria mutica (INP 143.909\%). mampu tumbuh hingga di ketinggian 3000 mdpl dengan suhu optimal $30-35^{\circ} \mathrm{C}$ (Fanindi dan Prawiradiputra, 2005). Hal ini sesuai dengan ketinggian tempat pengambilan data yaitu 1.183 mdpl.

\section{Syzygium oleina}

Syzygium oleina (INP 32.076\%) banyak ditemukan di stasiun 6 yang merupakan jalur erupsi merapi. Sehingga disana banyak ditemui hutan primer namun sebagian ada yang sekunder. Tumbuhan ini paling banyak ditemukan pada permukaan tanah yang lebih tinggi. Tumbuhan ini memiliki daya serap air yang tinggi dan membutuhkan intensitas cahaya yang cukup untuk proses fotosintesis.

Berdasarkan pengolahan data yang dilakukan didapatkan indeks nilai penting (INP) tertinggi setiap habitus seperti pada tabel berikut:

Tabel 1. Indeks Nilai Penting Tertinggi dan Kerapatan Jenis

Table 1. Highest Importance Value Index and Species Density

\begin{tabular}{lllccc}
\hline No & Habitus & $\begin{array}{c}\text { Nama Ilmiah } \\
\text { (Scientific name })\end{array}$ & $\begin{array}{c}\text { Nama Lokal } \\
\text { (Local name) }\end{array}$ & $\begin{array}{c}\text { INP } \\
\text { (Importance } \\
\text { value index }) \\
(\%)\end{array}$ & $\begin{array}{c}\text { Kerapatan } \\
\text { Jenis } \\
\left(\begin{array}{c}\text { Density) } \\
(\mathrm{N} / \mathrm{Ha})\end{array}\right.\end{array}$ \\
\hline 1. & Lumut & Pogonatum sp. & Lumut Daun & $203,314 \%$ & $0,094 \mathrm{~N} / \mathrm{Ha}$ \\
2. & Herba & Ageratina reparia & Roro Ireng & $124,761 \%$. & $1,717 \mathrm{~N} / \mathrm{Ha}$ \\
3. & Semak & Brachiria mutica & Rumput Malela & $141,488 \%$. & $9,766 \mathrm{~N} / \mathrm{Ha}$ \\
4. & Pohon & Syzygium oleina & Pucuk Merah & $111,333 \%$. & $0,033 \mathrm{~N} / \mathrm{Ha}$ \\
\hline
\end{tabular}

Habitus lumut yang mempunyai Indeks Nilai Penting tertinggi yaitu Pogonatum sp. dengan INP sebesar 203,314\%. Berdasarkan hasil perhitungan didapatkan hasil INP tertinggi pada habitus herba yaitu pada spesies Ageratina reparia dengan INP $124,761 \%$. Menurut (Muttaqien, 2004) mengatakan bahwa Ageratina riparia merupakan spesies tumbuhan yang biasa terdapat di daerah pegunungan hutan sekunder, di daerah terbuka atau setengah terbuka. Tumbuhan ini merupakan tumbuhan terrestrial yang merupakan salah satu dari tumbuhan memiliki jumlah individu dan INP tinggi. Berdasarkan 
Analisis Vegetasi Di Taman Nasional Gunung Merapi A.F.Parwati, Z.Aptari, R.D. Saputri, A.M.Akbarudin, A.G.Kirana, S.T.Wahyuni

hasil perhitungan didapatkan hasil INP tertinggi pada habitus semak yaitu pada spesies Brachiria mutica dengan INP 141,488\%. Hal ini dapat diartikan bahwa spesies Brachiria mutica mendominasi di dalam ekosistem tersebut. Berdasarkan hasil perhitungan didapatkan hasil INP tertinggi pada habitus Pohon yaitu pada spesies Syzygium oleina dengan INP 111,333\%. Syzygium oleana atau pucuk merah berkerabat dekat dengan tanaman jambu air, salam, Juwet, jambu Darsono, klampok watu (jambu batu) dari genus Syzygium, Dengan 1.200 spesies, Syzygium adalah genus terbesar di Myrta- ceae. Ini memiliki distribusi subtropis ke tropis (Parnell JAN, Craven LA, Biffin E. 2006).

Dalam rangka mengetahui

keanekaragaman jenis, metode perhitungan menggunakan perhitungan indeks ShanonnWiener. Data INP yang sebelumnya dihitung dapat digunakan untuk menghitung Indeks Shanonn-Weiner per habitus.

Tabel 2. Indeks Shannon-Wiener per habitus Table 2. Shannon-Wiener index per habitus

\begin{tabular}{lll}
\hline No & Habitus & $\begin{array}{l}\text { Indeks } \\
\text { Shanonn- } \\
\text { Wiener }\end{array}$ \\
\hline 1. & Lumut-Lichen & 0,349 \\
2. & Herba & 0,880 \\
3. & Semak & 0,709 \\
4. & Pohon & 0,782 \\
\hline
\end{tabular}

Pada habitus lumut didapatkan indeks Shanonn-Wiener sebesar 0,349. Pada habitus herba didapatkan indeks Shanonn-Wiener sebesar 0,880. Pada habitus semak indeks Shanonn-Wiener sebesar 0,709. Sedangkan pada habitus pohon indeks Shanonn-Wiener sebesar 0,782. Berdasarkan indikator indeks Shanonn-Wiener, keanekaragaman jenis pada Stasiun Penelitian termasuk dalam kategori rendah karena kurang dari 1, 5. Dari keempat habitus tersebut yang memiliki keanekaragaman jenis yang tertinggi yaitu habitus lumut, kemudian pada habitus semak, pohon kemudian herba.

Berdasarkan data yang didapat, kerapatan jenis pada masing-masing habitus di Taman Nasional Gunung Merapi yaitu habitus lumut sebesar 0,042 N/Ha. Pada habitus Herba kerapatan sebesar 0,229 N/Ha. Pada habitus Semak didapatkan kerapatan sebesar 1,858 N/Ha, sedangkan pada habitus Pohon didapatkan kerapatan sebesar 0,028 N/Ha. Berdasarkan kerapatan jenis yang didapat, yang memiliki kerapatan jenis paling tinggi yaitu pada habitus semak, kemudian herba, lumut-lichen dan yang memiliki kerapatan paling rendah yaitu pada habitus pohon

Hasil Analisis Vegetasi menujukan bahwa vegetasi di Stasiun Penelitian tumbuh dengan subur, hal tersebut dikarenakan saat erupsi Gunung Merapi kawasan tersebut termasuk suksesi sekunder, suksesi sekunder terjadi bila suatu komunitas atau ekosistem alami terganggu baik secara alami atau buatan dan gangguan tersebut tidak merusak total tempat tumbuh organisme sehingga dalam komunitas tersebut substrat lama dan kehidupan masih ada dan masih bisa tumbuh spesies-spesies tanpa menunggu waktu yang lama. (Mueller-dombois and Ellenberg, 1974).

\section{KESIMPULAN}

1. Indeks Nilai Penting (INP) habitus lumut tertinggi Pogonatum sp. 203,314\%, INP habitus INP Herba tertinggi Ageratina reparia $124,761 \%$. INP Semak tertinggi Brachiria mutica $141,488 \%$. INP untuk tingkatan pohon tertinggi adalah Syzygium oleina $111,333 \%$.

2. Nilai Kerapatan tertinggi adalah Semak (Brachiria mutica) dengan nilai Kerapatan Jenis 9,766 N/Ha. Nilai Kerapatan berhubungan dengan Indeks Nilai Penting (INP) dan Indeks Shannon-Wiener. Semakin tinggi kerapatan jenis maka INP 
semakin tinggi sedangkan Indeks Shannon-Wiener semakin rendah.

3. Pada habitus lumut-lichen didapatkan indeks sebesar 0,349. Pada habitus herba didapatkan indeks Shanonn-Wiener sebesar 0,880. Pada habitus semak indeks Shanonn-Wiener sebesar 0,709. Sedangkan pada habitus pohon indeks Shanonn-Wiener sebesar 0,782. Indeks Shannon semakin tinggi indeks shanon maka tingkat keanekaragaman hayati yang ada di wilayah tersebut semakin tinggi.

Berdasarkan indikator indeks ShanonnWiener, keanekaragaman jenis pada Stasiun Penelitian termasuk dalam kategori rendah.

\section{DAFTAR PUSTAKA}

Agus Andoko. 2003. Budi Daya Bambu Rebung. Yogyakarta: Kanisus.

Ani Mardiastuti. 1999. Keanekaragaman Hayati:Kondisi dan Permasalahannya. Bogor: Fakultas Kehutanan IPB.

Berlin, N.V.A., dan Estu. R., 1995. Jenis Dan Prospek Bisnis Bambu. Penebar

Dyna Natalia dan Trikinasih Handayani. 2013. Analisis Vegetasi Strata Semak Di Plawangan Taman Nasional Gunung Merapi Pasca Erupsi Merapi 2010. Jurnal Bioedukita. Vol $\underline{1, \text { No } 1 .}$.

Ewusie, J.Y. 1990. Ekologi Tropika. Bandung: ITB Fachrul, M.F. 2008. Metode Sampling Bioekologi. Jakarta.

Fanindi dan Prawiradiputra. 2005. Karakterisasi dan Pemanfaatan Rumput Brachiaria sp. Bogor: Balai Penelitian Ternak

Hill, D., Fasham, M., Tucker, G., Shewry, M., \& Shaw, P. (Eds.). (2005). Handbook of Biodiversity Methods: Survey, Evaluation and Monitoring. Cambridge: Cambridge University Press.

Hingmadi, denianus, 2012. Keanekaragaman Ciri Morfologi Jenis-Jenis Bambu (Bambusa Sp.) Di Kelurahan Teunbaun Kecamatan Amarasi Barat Kabupaten Kupang. Kupang : FMIPA UPGRI.
Jakarta: Swadaya.

Johnson J, E Mitchem dan D Kreh, E Richard. 2003. Mendirikan paulownia kerajaan di Virginia Piedmont. Hutan Baru 25: 11-23.

Lakitan, B. 2002. Dasar Dasar Klimatologi. PT. Raja Grafindo Persada. Jakarta.

Maharadatunkamsi, Prakarsa, Tatag Bagus Putra dan Kurnianigsih. 2015. Struktur Komunitas Mamalia Di Cagar Alam Leuweung Sancang, Kabupaten Garut, Jawa Barat. Zoo Indonesia 2015. 24(1):51-59.

Mueller-Dombois, D dan H. Ellenberg. 1974. Aims and Methods of Vegetation Ecology. John Wiley and Sons . New York.

Muttaqien, Santoso P, Kusmoro J. 2004. Studi Vegetasi Hutan Hujan Tropis Pegunungan di Gunung Manglayang Jawa Barat.

Otjo Dan Atmadja, 2006. Bambu,Tanaman Tradisional Yang Terlupakan.

Parnell JAN, Craven LA, Biffin E. 2006. Matters of scale: dealing with one of the largest genera of angiosperms. In: Hodgkinson TR, Parnell JAN (eds),

Reconstructing the Tree of Life: Taxonomy and systematics of species rich taxa: 251-273. CRC Press.

Santoso, Yatno. 2008. Studi Keanekaragaman Mamalia Pada Beberapa Tipe Habitat Di Stasiun Penelitian Pondok Ambung Taman Nasional Tanjung Puting Kalimantan Tengah. Media Konservasi. Vol. 13, No. 3.

Solfiyeni, Chairul, dan Masdalena Marpaung. 2016. Analisis Vegetasi Tumbuhan Invasif di Kawasan Cagar Alam Lembah Anai, Sumatera Barat. Proceeding Biology Education Conference. Vol 13(1): 743-747.

Susantyo, J. M. 2011. "Inventarisasi Keanekaragaman Jenis Tumbuhan di Kawasan taman Nasional Gunung Merapi.” Skripsi. Departemen Konservasi Sumberdaya Hutan dan Ekowisata: Fakultas Kehutanan IPB.

Windadri, Florentina Indah. 2009. "Keanekaragaman Lumut pada Marga Pandanus di Taana Nasional Ujung Kulon Banten”. Jurnal Natur Indonesia, 11 (2):8993. 